Revue d'histoire de l'Amérique française

REVUE D.HISTOIRE DE L'AMÉRIQUE FRANÇAISE

\title{
Mise au point de Desmond Morton à propos du livre de Jacques
} Gouin

\section{Bon coeur et bon bras : histoire du régiment de Maisonneuve} 1880-1980

\section{Desmond Morton}

Volume 37, numéro 1, juin 1983

URI : https://id.erudit.org/iderudit/304144ar

DOI : https://doi.org/10.7202/304144ar

Aller au sommaire du numéro

Éditeur(s)

Institut d'histoire de l'Amérique française

ISSN

0035-2357 (imprimé)

1492-1383 (numérique)

Découvrir la revue

Citer ce document

Morton, D. (1983). Mise au point de Desmond Morton à propos du livre de Jacques Gouin : bon coeur et bon bras : histoire du régiment de Maisonneuve 1880-1980. Revue d'histoire de l'Amérique française, 37(1), 120-120.

https://doi.org/10.7202/304144ar d'utilisation que vous pouvez consulter en ligne. 


\section{MISE AU POINT DE DESMOND MORTON À PROPOS DU LIVRE DE JACQUES GOUIN}

Bon coeur et bon bras: histoire du régiment de Maisonneuve 1880-1980

Monsieur Jacques Gouin a attiré mon attention sur une observation de ma critique de son Histoire du régiment de Maisonneuve, selon laquelle ce livre révélerait «... un manque pur et simple d'honnêteté...» (Revue d'histoire de l'Amérique française, 36,4 (mars 1983): 593).

Ce jugement constitue une interprétation totalement erronée de mon intention, qui était simplement de souligner l'absence dans ce livre de certains épisodes bien connus de l'histoire du régiment de Maisonneuve.

La lacune que je voulais signaler ne fait que refléter les difficultés que comporte la rédaction sur commande de tout ouvrage d'histoire, et ne porte nullement atteinte à l'intégrité, à l'honneur et à la réputation professionnelle de mon très estimé collègue $\mathrm{M}$. Gouin. 